\title{
A corneal abnormality associated with trisomy 8 mosaicism syndrome
}

\author{
D J STARK, ${ }^{1}$ D W GILMORE, ${ }^{2} \mathrm{~J}$ C VANCE,${ }^{3}$ AND J H PEARN ${ }^{3}$
}

From the 'Mater Children's Hospital, South Brisbane, Queensland 4101, Australia; ${ }^{2}$ Lismore, New South Wales, 2480, Australia; and the ${ }^{3}$ Department of Child Health, University of Queensland, St Lucia, Queensland 4067, Australia

SUMmARY Eye abnormalities are a significant feature of trisomy 8 mosaicism syndrome. This paper gives the first account of the specific histopathology of a corneal opacity which is characteristic of this syndrome. The importance of early recognition is stressed because of potential therapeutic visual improvement. The necessity of including mosaic trisomy 8 in the differential diagnosis of such corneal opacities is illustrated by this case.

The trisomy 8 mosaicism syndrome is now recognised as having distinct clinical features which include mild to moderate mental retardation, characteristic facies and ears, and orthopaedic, cardiovascular, and genitourinary abnormalities. ${ }^{1-3}$ Characteristic dermatoglyphic patterns have also been described..$^{1-5}$ We report a case of a dense corneal opacity associated with the syndrome and offer some suggestions for management of the patient with such a lesion.

\section{Case report}

The patient was the first male child of unrelated Caucasian parents. The mother was aged 31 years and the father 28 years at the time of the birth. The mother had a normal daughter from a previous marriage.

A paediatrician (DWG) was consulted at birth because of unusual dysmorphic features which included frontal bossing, upturned nose, thick lips, and prominent ears with hypertrophic antihelices. These features are shown in Fig. 1 and 2 taken at 5 months of age prior to eye surgery. Chromosome studies confirmed the presence of trisomy 8 mosaicism $(46, X Y / 47, X Y,+8)$ in the child, while those of the parents were normal.

Ophthalmological findings were a dense opacity of the right cornea (Fig. 1) obscuring the pupil, and a divergent squint and bilateral nasolacrimal duct obstruction. At the age of 5 months an electroretinogram performed under general anaesthetic showed a

Correspondence to Dr J C Vance, Department of Child Health, University of Queensland, Mater Children's Hospital, South Brisbane, Queensland 4101, Australia. normal response to 40 check stimulus in the left eye but no response in the right. Flash stimuli resulted in a normal identical response from each eye. These

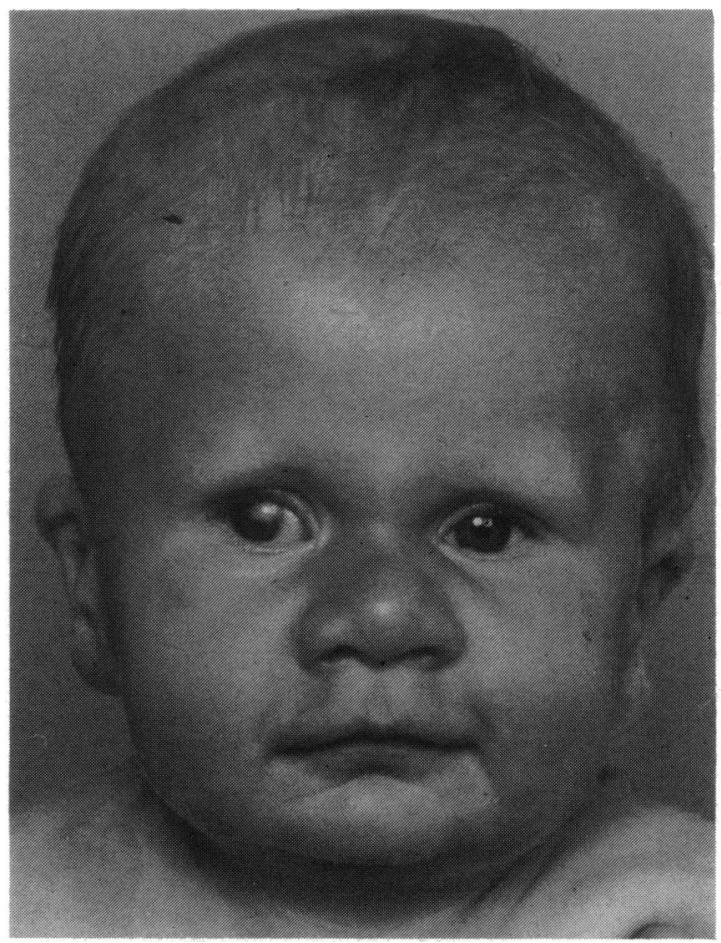

Fig. 1 Front view of child at 5 months of age showing characteristic facies and ears with the dense corneal opacity present in the right eye. 
results confirmed the integrity of the visual pathway but reduced vision in the right eye consistent with amblyopia.

The lesion was subsequently removed and penetrating keratoplasty performed. The pathologist reported a 'cream white tissue flake with some evidence of surface pigmentation while microscopy showed a dense plaque of richly vascularized fibrous tissue apparently of congenital origin' (Fig. 3).

Three months postoperatively the cornea remained clear. Although a right divergent squint was still present, the patient could fixate well with the right eye when the left was occluded. Further occlusion was deemed necessary to help overcome residual amblyopia.

\section{Discussion}

About 70 cases of trisomy 8 mosaicism have now been reported. ${ }^{3}$ The syndrome is distinguished by its characteristic facies, distinctive toe posture, absent or dysplastic patellae, joint contractures, and palmar or plantar furrows. Mental retardation is an almost uniform finding. ${ }^{3}$

Ocular manifestations are common in the syndrome, with strabismus occurring in almost half of the described cases. ${ }^{1-356}$ Deep set eyes have also been

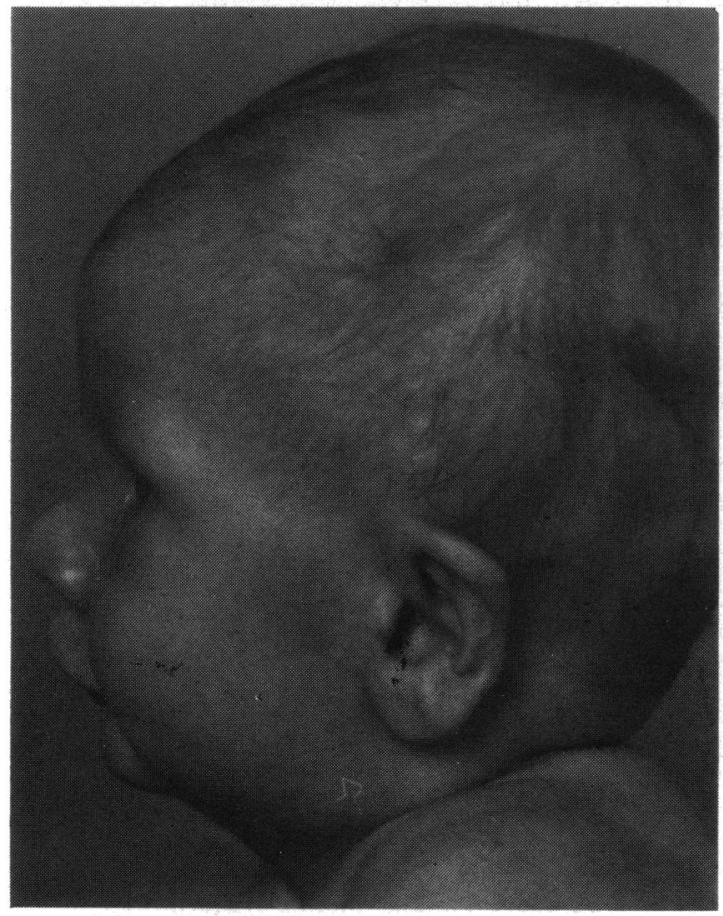

Fig. 2 Side view of child at 5 months of age showing dysmorphic features, particularly of the ears. reported. ${ }^{7}$ A congenital cataract and retrolental fibroplasia were noted in another child but were related to oxygen therapy for respiratory distress in the neonatal period. ${ }^{8}$

The present report describes a corneal opacity similar in appearance to those previously described, ${ }^{129}$ but the pathology of these lesions was not reported. Histologically the present lesion showed richly vascularised fibrous tissue. Corneal abnormalities are rare findings in children and the association with chromosomal disorders even rarer. Megalocornea has been described in Down's syndrome $\mathrm{e}^{10}$ and in association with multiple skeletal anomalies. ${ }^{11}$

Peters' anomaly (mesodermal dysgenesis of the cornea) is a rare developmental abnormality of the anterior segment of the eye and may present with congenital corneal opacities. ${ }^{12}{ }^{13}$ However, the lesion described in this paper was in the superficial layers of the cornea. Corneal opacities have also been described in other conditions, ${ }^{74-16}$ but the appearance of the corneal lesion is again quite different.

We present the fourth report of a child with

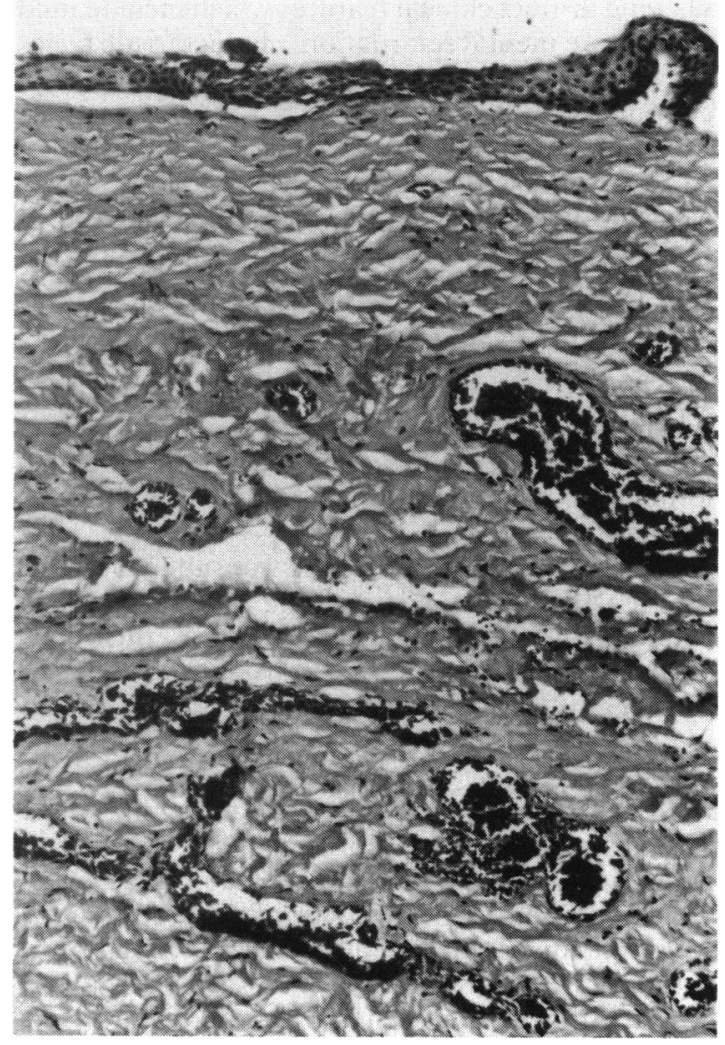

Fig. 3 Histopathology of corneal opacity showing richly vascularised fibrous tissue in the superficial layers of the cornea. 
trisomy 8 mosaicism and a corneal opacity and the first histological examination of such a lesion. It was found to be not consistent with Peters' anomaly. By the age of 5 months the child was unable to fixate on objects owing to occlusion amblyopia even though he had a normal electroretinogram. To prevent the development of amblyopia, recognition and treatment of the lesion soon after birth is essential. Removal of the lesion and subsequent corneal grafting is considered to be the treatment of choice if the pupil is occluded. Keratoplasty in the first three months is advisable to prevent amblyopia. Microsurgical techniques ${ }^{13}$ make this possible. Amblyopia may still be a problem owing to postoperative anisometropia but should respond to therapy. The latest report ${ }^{9}$ described $+4.5 \mathrm{D}$ hypermetropia in both eyes with several dense stromal opacities in the right eye. Recurrent examinations under anaesthetic showed no change over 12 months. This lesion did not appear to be obstructing the pupil.

The pathogenesis of the lesions is unclear ${ }^{9}$ but may represent areas of trisomic cells which have developed and then died, leading to scar formation.

Children with trisomy 8 mosaicism, although almost invariably mentally retarded, may have a life span of at least 20 years. ${ }^{10}$ To keep their intellectual and visual sensory handicap to a minimum, early recognition and treatment of this lesion is essential.

We are grateful to the staff of the cytogenetics laboratory at the Mater Misericordiae Hospital, Brisbane, to Dr J Sullivan for reporting on the pathology, and to Mrs V L Hawkins and Mrs P B Carter for typing assistance.

\section{References}

1 Fineman RM, Ablow RC, Howard RO, Albright J, Breg WR. Trisomy 8 mosaicism syndrome. Pediatrics 1975; 56: 762-7.
2 Cassidy SB, McGee BJ, van Eys J, Nance WE, Engel E. Trisomy 8 syndrome Pediatrics 1975; 56: 826-31.

3 Riccardi VM. Trisomy 8: an international study of 70 patients. Birth Defects: Original Article Series 1977; 13: 171-84.

4 Reyes PG, Hsu LYF, Strauss L, Rose J, Hirschhorn K. Trisomy 8 mosaicism syndrome. Report of monozygotic twins. Clin Genet 1978; 14: 90-7.

5 Rodewald A, Zankl H, Wischerath H, Borkowsky-Fehr B. Dermatoglyphic patterns in trisomy 8 syndrome. Clin Genet 1977; 12: 28-38.

6 Caspersson T, Lindsten J, Zech L, Buckton KE, Price WH. Four patients with trisomy 8 identified by the fluoresence and Giemsa banding techniques. J Med Genet 1972; 9: 1-7.

7 Smith DW. Recognizable patterns in human malformation. 3rd ed. Philadelphia: Saunders, 1982: 24-7.

8 Riccardi VM, Atkins L, Holmes LB. Absent patellae, mild mental retardation, skeletal and genitourinary anomalies, and C group autosomal mosaicism. J Pediatr 1970; 77: 664-72.

9 Frangoulis M, Taylor D. Corneal opacities-diagnostic feature of the trisomy 8 mosaic syndrome. Br J Ophthalmol 1983; 67: 619-22.

10 Rogers GL, Polomeno RC. Autosomal-dominant inheritance of megalocornea associated with Down's syndrome. Am J Ophthalmol 1974; 78: 526-9.

11 Frank Y, Zipkrowski M, Romano A, et al. Megalocornea associated with multiple skeletal anomalies: a new genetic syndrome? J Genet Hum 1973; 21: 67-72.

12 Bull MJ, Baum JL. Peters' anomaly with pulmonary hypoplasia. Birth Defects: Original Article Series 1976; 12: 181-6.

13 Waring GO, Rodrigues MM, Laibson PR. Anterior chamber cleavage syndrome. A stepladder classification. Sur Ophthalmol 1975; 20: 3-27.

14 Harbin RL, Katz JI, Frias JL, Rabinowicz IM, Kaufman HE. Sclerocornea associated with the Smith-Lemli-Opitz syndrome. Am J Ophthalmol 1977; 84: 72-4.

15 Townsend WM. Congenital corneal leukomas. I. Central defect in Descemet's membrane. Am J Ophthalmol 1974; 77: 80-86.

16 François J, Berger R, Saraux H. Report on chromosomal aberrations and ophthalmology presented to 79th Congress of the French Society of Ophthalmology. Arch Ophthalmol 1973; 89: 437.

Accepted for publication 1 April 1986. 